\title{
Stereological and comparative evaluation of the carpal tunnel in patients with carpal tunnel syndrome using magnetic resonance images
}

\author{
Gülser Ak Güven", Mehmet Emirzeoğlub ${ }^{\mathrm{b}}$, Bünyamin Şahin ${ }^{\mathrm{b}}$, Kemal Balcı $^{\mathrm{c}}$, Murat Terzic ${ }^{\mathrm{c}}$, Mustafa Bekir Selçuk ${ }^{\mathrm{d}}$ \\ ${ }^{a}$ Vocational School of Health Services, Ondokuz Mayls University, Samsun, Turkey \\ ${ }^{b}$ Deparment of Anatomy, Faculty of Medicine, Ondokuz Mayls University, Samsun, Turkey \\ ${ }^{c}$ Deparment of Neurology, Faculty of Medicine, Ondokuz Mayls University, Samsun, Turkey \\ ${ }^{d}$ Deparment of Radiology, Faculty of Medicine, Ondokuz Mayls University, Samsun, Turkey
}

\section{ARTICLE INFO}

\section{* Correspondence to:}

Gülser Ak Güven

Vocational School of Health Services, Ondokuz Mayıs University,

Samsun, Turkey

e-mail: gulser-ak@hotmail.com

\section{Keywords:}

Carpal tunnel syndrome

Carpal tunnel

Magnetic resonance images

Stereology

Volume and volume fraction

\section{ABSTRACT}

Carpal tunnel syndrome (CTS) is the most common entrapment neuropathy, which occurs as a result of the compression of the median nerve in the carpal tunnel of the wrist. The aim of this study is to evaluate the MR images of the carpal tunnel and to show the volume and volume fraction of the carpal tunnel contents to the total carpal tunnel volume in relation to CTS using the stereological methods. The study included 42 female participants (30 patients and 12 control), with age ranged between 19-60 years. Total of 80 wrists (60 patient and 20 control group) were examined. We examined the right and left sides of each participant. T1-weighted axial MR images of the wrists were done; images were analyzed using the ImageJ software. The mean volume of the carpal tunnel in patients and control were $\left(4.16 \mathrm{~cm}^{3} \pm 0.59\right.$ and $\left.3.87 \mathrm{~cm}^{3} \pm 0.43\right)$, respectively. Volume of carpal tunnel in patient group was found to be higher than control group $(\mathrm{p} \leq 0.05)$. The mean of the median $\mathrm{n}$. volume in patients and controls were $\left(0.398 \mathrm{~cm}^{3} \pm 0.081\right.$ and $\left.0.233 \mathrm{~cm}^{3} \pm 0.034\right)$, respectively. The median $\mathrm{n}$. volume in patient group was higher than the healthy group $(\mathrm{p} \leq 0.05)$. The mean volume fraction of the median nerve in patients and control were $\left(9.62 \mathrm{~cm}^{3} \pm 1.74\right.$ and $\left.6.02 \mathrm{~cm}^{3} \pm 0.72\right)$, respectively. There is significant difference for volume fraction of median nerve between patients and controls $(p \leq 0.05)$. In our study, the carpal tunnel volume, median nerve volume and volume fraction were higher in cases with CTS than those in healthy individuals. Our study is important due to supporting the diagnosis of CTS, as well as checking the possibility and progression of CTS by using of volumetric measurements as a marker. 